\title{
Working Group Consultation: Alloimmunity as a Vaccine Approach Against HIV/AIDS: National Institutes of Health Meeting Report, May 24, 2012
}

\author{
Anjali Singh, Jon Warren, Alan Schultz, Charles J. Hackett, ${ }^{1}$ and Opendra Sharma ${ }^{1}$
}

\begin{abstract}
Alloimmunization vaccine strategies propose to avoid the problem of the extreme antigenic variability of human immunodeficiency virus (HIV) by instead focusing on the cellular antigens incorporated into HIV virions as they bud from infected cells. This report summarizes a Consultation meeting convened by the National Institute of Allergy and Infectious Diseases, National Institutes of Health on May 24, 2012. The objectives of the meeting were to (1) reach a consensus on the essential questions surrounding alloimmunization as a strategy for vaccine design against HIV, and (2) determine the experimental elements that might be needed for addressing these questions in an optimized pilot framework nonhuman primate (NHP) protocol for allogeneic immunization. The Consultation revisited the rationale and concerns of vaccination to induce allogeneic immunity, one of the most potent natural immune responses. The panelists' consensus was that a carefully designed skin graft transplant pilot experiment, in major histocompatibility complex (MHC) disparate male Mauritian cynomolgus macaques (MCM; Macaca fascicularis), would be useful for initially evaluating if alloimmunization results in an effective or even a partially effective safe AIDS vaccine. A successful NHP study for allogeneic immunization would provide further opportunities to explore vaccine-elicited immune and genetic correlates of protection against the acquisition of viral infection.
\end{abstract}

\section{Introduction}

T HE RATIONALE FOR CONSIDERING alloimmunization, that is vaccination aimed at the non-self MHC molecules incorporated into HIV particles, as a possible strategy for AIDS prophylactic vaccine development was presented more than 10 years ago. ${ }^{1,2}$ It is now reassessed on the basis of additional findings on the pivotal role of MHC in configuring innate and adaptive immune responses ${ }^{3,4}$ that have generated renewed interest in allogeneic immunity.

The recent Consultation brought together a diverse panel (Table 1) to address the still unsettled question of whether alloimmunization alone can induce a measurable degree of significant protection from virus acquisition, and to evaluate the current challenges and opportunities to rationally design a pilot nonhuman primate (NHP) protocol for demonstrating alloimmunity. Two alternatives emerged from the Consultation: determining whether allo-mediated protection from simian immunodeficiency virus (SIV) infection exists at all, or alternatively, if alloantigens would be successful only as an adjuvant or cofactor with viral antigens to generate a broadly effective prophylactic vaccine. The Consultation members emphasized that the question of alloantigen-based protection should first be addressed in a well-defined and controlled experimental system.

\section{Alloimmunization as a Vaccine Approach}

Dr. Gene Shearer reviewed and summarized the history of alloimmunization as an AIDS vaccine approach, some of which is briefly cited here.

A study of vertical perinatal transmission of HIV indicated that transmission of HIV from mother to child occurs more frequently among uniparous women ${ }^{5}$ who have not yet developed any anti-allo response to the fetus. Potent cell-mediated immunity to allogeneic leukocytes observed at birth in cord blood $^{6}$ might account for the additional observation that mother-to-child HLA class I concordance associates with increased prenatal HIV transmission. ${ }^{7}$ Furthermore, a cohort of HIV-exposed seronegative patients was identified in couples,

\footnotetext{
${ }^{1}$ Division of AIDS, National Institute of Allergy and Infectious Diseases, National Institutes of Health, Bethesda, Maryland.

${ }^{2}$ Division of Allergy, Immunology and Transplantation, National Institute of Allergy and Infectious Diseases, National Institutes of Health, Bethesda, Maryland.
} 
Table 1. Panelists to the "Working Group Consultation on Alloimmunity as a Vaccine Approach," National Institutes of Health Meeting, MAY 24, 2012

\begin{tabular}{|c|c|}
\hline Panelists & Affiliations \\
\hline Arthur, Larry & $\begin{array}{l}\text { National Institutes of } \\
\text { Health, Maryland }\end{array}$ \\
\hline Boasso, Adriano & $\begin{array}{l}\text { Imperial College London, } \\
\text { United Kingdom }\end{array}$ \\
\hline Bogers, Wilhelmus & $\begin{array}{l}\text { Biomedical Primate Research } \\
\text { Centre, Netherlands }\end{array}$ \\
\hline Bridges, Nancy & $\begin{array}{l}\text { National Institutes of Health, } \\
\text { Maryland }\end{array}$ \\
\hline Carrington, Mary & $\begin{array}{l}\text { National Institutes of Health, } \\
\text { Maryland }\end{array}$ \\
\hline Conley Anthony & $\begin{array}{l}\text { National Institutes of Health, } \\
\text { Maryland }\end{array}$ \\
\hline Cranage, Martin & $\begin{array}{l}\text { St George's University of London, } \\
\text { United Kingdom }\end{array}$ \\
\hline Gotch, Frances & $\begin{array}{l}\text { Imperial College London, } \\
\text { United Kingdom }\end{array}$ \\
\hline Graham, David & $\begin{array}{l}\text { Johns Hopkins University, } \\
\text { Maryland }\end{array}$ \\
\hline Hackett, Charles & $\begin{array}{l}\text { National Institutes of Health, } \\
\text { Maryland }\end{array}$ \\
\hline Kirk, Allan & $\begin{array}{l}\text { Emory University School of } \\
\text { Medicine, Georgia }\end{array}$ \\
\hline Kraemer, Kristy & $\begin{array}{l}\text { National Institutes of Health, } \\
\text { Maryland }\end{array}$ \\
\hline Lehner, Thomas & $\begin{array}{l}\text { Kings College London, United } \\
\text { Kingdom }\end{array}$ \\
\hline O'Connor, David & $\begin{array}{l}\text { University of Wisconsin, } \\
\text { Wisconsin }\end{array}$ \\
\hline Page, Mark & $\begin{array}{l}\text { National Institute for Biological } \\
\text { Standards and Control, } \\
\text { United Kingdom }\end{array}$ \\
\hline Schultz, Alan & $\begin{array}{l}\text { National Institutes of Health, } \\
\text { Maryland }\end{array}$ \\
\hline Shapiro, Stuart & $\begin{array}{l}\text { National Institutes of Health, } \\
\text { Maryland }\end{array}$ \\
\hline Sharma, Opendra & $\begin{array}{l}\text { National Institutes of Health, } \\
\text { Maryland }\end{array}$ \\
\hline Shearer, Gene & $\begin{array}{l}\text { National Institutes of Health, } \\
\text { Maryland }\end{array}$ \\
\hline Singh, Anjali & $\begin{array}{l}\text { National Institutes of Health, } \\
\text { Maryland }\end{array}$ \\
\hline Warren, Jon & $\begin{array}{l}\text { National Institutes of Health, } \\
\text { Maryland }\end{array}$ \\
\hline
\end{tabular}

in which only one partner is HIV infected, thus implying a potential role of HLA-mediated resistance to HIV. ${ }^{8}$ Unprotected heterosexual and homosexual intercourse elicits allogeneic responses in both partners, which might contribute to protection against HIV infection. ${ }^{9}$ Thus, the recognition of specific HLA alloantigens, expressed on the surface of $\mathrm{HIV}^{10}$ and containing a common epitope with viral envelope protein, ${ }^{11}$ might contribute to protection against both vertical and horizontal HIV transmission.

Although xenogeneic immunization of macaques has been protective against human cell-grown SIV whether virus particles, uninfected cells, or purified class II HLA antigens were used to immunize, ${ }^{12-14}$ duplicating this result with alloimmunization has been less successful. Alloimmunization with simian peripheral blood mononuclear cells (PBMCs) protected just $4 / 24$ macaques from SIV infection. ${ }^{15}$ In addition, alloimmunization with a simian B cell line expressing MHC class I and II molecules induced antibodies to class I but not class II and failed to prevent infection when macaques were challenged with $\operatorname{SIV}_{\text {mac }}$ grown in an allogeneic spleen. ${ }^{16}$ The results imply that the path to successful alloimmunization may be difficult. Recently, Dr. Thomas Lehner linked Mamu class I and II gene products with HIV gp140, SIV p27, and Hsp70 to a dextran polymer as a vaccine that combined both alloantigens and viral antigens.

After multiple exposure challenges with simian/human immunodeficiency virus (SHIV) SF162.P4 by the rectal route, three of nine macaques were protected from infection and the other six showed a significant decrease in the peak and sequential viral RNA concentrations compared to nine controls that all became infected. ${ }^{17}$ In another mucosal alloimmunization study, applying unmatched mononuclear cells to rectal or vaginal mucosa decreased the SIV infectivity of $\mathrm{CD}^{+}$ T cells ex vivo, though the efficacy of this treatment was not examined by in vivo challenge. ${ }^{18}$ In humans, in vitro and ex vivo infectivity of $\mathrm{CD}^{+} \mathrm{T}$ cells by primary or laboratoryadapted HIV was notably decreased after in vivo alloimmunization. ${ }^{19,20}$

\section{Advantages and Disadvantages of Alloimmunization}

Table 2 summarizes the risks and potential benefits of alloimmunization, as highlighted by the Consultation. Extreme variability and mutability of HIV are major obstacles to AIDS vaccine development. Alloimmunization strategies propose to avoid this problem and focus instead on cellular antigens that are incorporated into HIV as it buds from the cell. Nonetheless, "breadth" and durability of the anti-allo response similarly will need to be addressed.

Potential disadvantages to the concept were discussed. Vaccination to induce or enhance allogeneic immunity would require careful study to rule out possible reactions that could cause autoimmune or other detrimental immunologic conditions. Successful alloimmunization would create an obstacle to subsequent organ transplant, should it be needed, in vaccine recipients, and could contribute to poor outcome after transplantation. However, in the nontransplant setting, it was noted that more than 2,000 women who have recurrent spontaneous abortions had received multiple immunizations with their partners' leukocytes without detectable side effects, but did show reduced in vitro HIV infection. ${ }^{21}$ Detrimental effects associated with exposure to different HLA types are not commonly observed in individuals who have received multiple transfusions. ${ }^{22}$ And it was further argued that in HIV-endemic regions, the risk-to-benefit ratio of successful alloimmunization to prevent HIV infection would outweigh potential allograft failure.

However, the goal of the Consultation was not to determine whether an alloimmunization strategy should be pursued, but rather the more limited goal of proposing and discussing what NHP studies might clarify the path forward.

\section{Pilot NHP Framework Protocol for Alloimmunization}

Table 3 summarizes the key questions and concerns regarding an alloimmunity approach in accelerating the efforts to design a preventive AIDS vaccine. Dr. Jon Warren presented a novel pilot NHP vaccination/challenge framework 
Table 2. Rationale of Considering Alloimmunization as a Strategy for AIDS Vaccine, National Institutes of Health Meeting, May 24, 2012

\begin{tabular}{l} 
Advantages \\
\hline Results in rapid and \\
potent primary HLA- \\
specific response \\
Might activate multiple \\
innate antiviral factors: \\
CD8-SF, RANTES, MIP-1 $\alpha$, 3 , EDN, and APOBEC3G \\
MIP-1 $\beta$, EDN \\
Might induce anti-CCR5 \\
antibodies and down regulates \\
CCR5 and CXCR4 expression
\end{tabular}

Leads to anti-HLA antibody memory immunity

Immunologically independent of cytotoxic T lymphocyte and antibody escape as immune response is indifferent to viral mutations

Provides sterilizing immunity

Causes no adverse side effects in recurrent spontaneously aborting women immunized with their partner's HLA
Disadvantages

Vaccine complexity might expand HLA-specific $\mathrm{CD} 4{ }^{+}$virus target cells for infection

Elevated innate antiviral factors might not exhibit significant immunologic memory

Might observe different degrees of protection depending on the level of HLA matching and thus need immunization against multiple HLA haplotypes to induce protection

Duration of the protection might be limited

Immunity is not virus specific

Vaccine needs to be sterilizing as HLA carried by virus remains allogeneic only in the absence of infection

HLA types of potential HIVinfecting contacts are unknown

Could exclude vaccine recipients from receiving transplants

Might induce autoimmune or other detrimental immunologic conditions
Table 3. Key Questions Addressed in the “Working Group Consultation on Alloimmunity as a Vaccine Approach," National Institutes of Health MeEting, MAY 24, 2012

Efficacy

1. Could alloimmunization, by itself, induce protection from HIV/SIV acquisition?

2. What unique features does an alloimmunity-based AIDS vaccine have compared to other vaccines?

3. Could a alloimmunization-based vaccine be considered in combination with other AIDS vaccines?

4. Could alloantigens function as adjuvant/cofactor for HIV/SIV antigens for boosting viral-specific responses?

5. Could the induction of long-lasting protection and immunologic memory be achieved by alloimmunization?

Immune response

1. What immunologic barriers need to be overcome for an alloimmunization-based vaccine?

2. What are the effects of coincident administration of alloantigens on induction of HIV /SIV-specific immunity?

3. Have alloimmunization studies simultaneously tested the adaptive and innate immunity for protective synergy?

4. How would multiple HLA antigens be introduced in the immunogen? How many?

NHP validation

1. What is the goal of a pilot framework NHP protocol for an allogeneic immunization study?

2. What are the challenges for optimizing the NHP protocol for allomediated protection?

3. What experimental elements are needed to test allogeneic protection in NHP?

4. Which is the best available NHP subspecies for a pilot NHP alloimmunization protocol?

5. What are the possible alloimmunization-based vaccine constructs for an NHP protocol?

6. What are the limitations of challenge viruses in preclinical AIDS vaccine studies?

7. What are the immunologic/virologic readouts for an alloimmunity-based vaccine in NHP?

8. What level of protection is needed to define success of alloimmunization in NHP?

Translational feasibility

1. What are the potential outcomes and feasible next steps if protection from acquisition is observed in an NHP vaccination/challenge protocol?

2. What are the major clinical, safety, regulatory, and ethical considerations for alloimmunization studies?

3. What are the confounding risk factors that may influence the effect of alloimmunity on HIV/SIV transmission?

4. How to address the concern that an alloimmune response would have detrimental consequences in the setting of organ transplantation?

SIV, simian immunodeficiency virus; NHP, nonhuman primate.

\section{NHP subspecies}

Although the Indian-origin rhesus macaque (Macaca mulatta) has been extensively utilized as the SIV macaque model for AIDS, to characterize and generate challenge viruses, and to understand the virology and pathogenesis of infection, this subspecies displays extensive MHC genetic diversity, with multiple haplotypes and significant gene copy number variation. The available animals are a relatively outbred population useful for testing vaccine concepts for eventual use in humans, but the relatively high level of MHC diversity in protocol for allogeneic immunization, and Dr. Alan Schultz moderated the subsequent deliberations such that a consensus was achieved on a number of variables, including (1) NHP subspecies, (2) challenge virus, (3) immunogens and pilot study design, (4) immune responses to assess, (5) assays and reagents, and (6) feasible next steps-if indeed significant protection from acquisition is observed. The major issues discussed by the Consultation in this regard are presented in Table 4 and are described below. 
Table 4. Principal Components of a Pilot Framework Nonhuman Primate Protocol Drafted in the

"Working Group Consultation on Alloimmunity as

a Vaccine Approach," National Institutes of Health MeEting, May 24, 2012

\begin{tabular}{|c|c|}
\hline NHP protocol components & Recommendations \\
\hline NHP subspecies & $\begin{array}{l}\text { Mauritian cynomolgus } \\
\text { macaques (MCM) with } \\
\text { well-defined MHC } \\
\text { class I and class II alleles }\end{array}$ \\
\hline \multicolumn{2}{|l|}{ Challenge virus } \\
\hline Specificity & $\begin{array}{l}\text { Molecular clone of } \\
\text { pathogenic } \mathrm{SIV}_{\operatorname{mac} 239}\end{array}$ \\
\hline Stock & $\begin{array}{l}\text { In vitro (PBMC) and } \\
\text { in vivo (infection } \\
\text { followed by ex vivo } \\
\text { spleen culture) to recover } \\
\text { and pool virus from } \\
\text { haplotype-matched MCM } \\
\text { In vivo titration and } \\
\text { biochemical characterization } \\
\text { of glycoforms, cytokines, } \\
\text { and alloantigens }\end{array}$ \\
\hline Route & Mucosal (rectal) \\
\hline Dose & $\begin{array}{l}\text { Repeat low-dose exposure } \\
\text { for a minimally infectious } \\
\text { dose such that the control } \\
\text { group is infected by three } \\
\text { to four weekly exposures }\end{array}$ \\
\hline Immunogen & Skin graft transplantation \\
\hline Pilot study design & $\begin{array}{l}\text { Test if MHC disparate skin } \\
\text { graft in male MCM leads } \\
\text { to alloimmunization against } \\
\text { mucosal } \text { SIV }_{\text {mac239 }}\end{array}$ \\
\hline Immune responses & $\begin{array}{l}\text { Functional profiles of humoral, } \\
\text { cellular, and innate immune } \\
\text { cells; viremia }\end{array}$ \\
\hline $\begin{array}{l}\text { Assays and } \\
\text { reagents resources }\end{array}$ & $\begin{array}{l}\text { MHC class I/II tetramers } \\
\text { coupled flow cytometry } \\
\text { and ELISpot for specificity, } \\
\text { phenotype, and quantitation } \\
\text { of allo-T and B cell responses }\end{array}$ \\
\hline $\begin{array}{l}\text { Feasible next steps if } \\
\text { protection from } \\
\text { acquisition is observed }\end{array}$ & $\begin{array}{l}\text { Collected serum use for } \\
\text { passive transfer NHP } \\
\text { studies to elucidate } \\
\text { antibody-mediated } \\
\text { protection against challenge } \\
\text { Identification of human } \\
\text { cohorts/HLA typing } \\
\text { databases to complement } \\
\text { the protective effect of } \\
\text { alloimmunization with } \\
\text { epidemiologic studies }\end{array}$ \\
\hline
\end{tabular}

NHP, nonhuman primate; PBMC, peripheral blood mononuclear cells.

these macaques greatly complicates focused experimental testing of an alloimmunization concept.

Dr. Jon Warren proposed instead the use of Mauritian cynomolgus macaques (MCM) for this purpose because these animals have well-defined MHC genetics that show extremely limited MHC genetic diversity. Panelist Dr. David $\mathrm{O}^{\prime}$ Connor presented his highly detailed studies of MCM genetics. MCM are geographically isolated and descend from a small founder population with only seven major haplotypes termed M1 through M7. ${ }^{23}$ The MHC alleles of each of these seven haplotypes are known. Limited sharing of MHC class I alleles is evident among different MCM haplotypes, along with no MHC class II sharing. This limited MHC haplotype diversity makes MCM a particularly attractive model for characterizing MHC class II alleles and to advance our understanding of host genetic effects in SIV /SHIV models of HIV infection. Dr. Mark Page also shared data on the association between haplotype M3 with early control of $\mathrm{SHIV}_{\text {sbg }}$ infection and an M6 link with elevated $\mathrm{SHIV}_{\text {sbg }}$ viremia. ${ }^{24}$ These MCM were susceptible to challenge with high-dose $\mathrm{SIV}_{\text {mac239 }}$ grown on rhesus PBMCs, had uniform peak viral loads $>10^{6}$, and exhibited MHC-dependent chronic viral loads of $10^{4-5}$. The consensus of the panelists was to use MCM with well-defined MHC class I and class II alleles for any alloimmunization pilot protocol.

\section{Challenge virus}

Rhesus macaques can be infected with various SIV and SHIV challenge strains of differing virulence to better understand viral pathogenesis or to explore the potential protective efficacy of vaccine concepts. ${ }^{25}$ Panelists addressed the potential limitations of various challenge viruses in preclinical AIDS vaccine studies. For instance, a virus that replicates very poorly in a host might be misleadingly easy to protect against by vaccination, and may be of little value for studying viral pathogenesis. Conversely, vaccine studies that employ highly pathogenic experimental challenge viruses delivered at high doses via intravenous inoculation might underestimate the potential protective efficacy of diverse immunization protocols. The Consultation advised the use of the highly pathogenic $\mathrm{SIV}_{\text {mac239 }}$ molecular clone for any pilot NHP alloimmunization protocol. Furthermore, based on available data, the members unanimously agreed on repeated low-dose intrarectal $\mathrm{SIV}_{\text {mac239 }}$ challenge to aim for a minimally infectious dose such that the control group is infected after no more than three or four weekly mucosal exposures.

Dr. David O'Connor proposed generating an in vitro SIV $_{\text {mac239 }}$ challenge stock in MCM PBMCs, and then in addition to characterizing this stock biochemically, having this stock titrated intrarectally in MCM to establish an appropriate repeated low-dose challenge benchmark. As an alternative, Dr. Martin Cranage suggested infecting MCM in vivo followed by harvesting spleen cultures to recover and pool hightiter virus from several haplotype-matched MCM. However, limited virus evolution occurring in vitro might be preferable to in vivo selection. Knowing the antigenic composition (especially alloantigens) of the challenge stock will be essential and extensive characterization by mass spectrometry should be done. Dr. David Graham suggested that this could be achieved with existing technology employing extensive protein prefractionation and quantitation. Analysis of glycoforms and cytokine profiles should be obtained as well. It likely would require about 1 year to properly prepare and characterize a suitable MCM PBMC-derived SIV $_{\text {mac239 }}$ challenge stock for the contemplated pilot NHP study.

\section{Immunogens and pilot study design}

Designing immunogens capable of eliciting and maintaining immune responses that prevent the acquisition of 
HIV/SIV infection remains a major obstacle to the development of an AIDS vaccine. The obstacles are no less complex for alloantigens.

In addition to quality control measures to ensure their suitable expression and stability, maintaining the conformational integrity and native structures of alloantigens is critical in evaluating their protective efficacy. Panelists considered the plausibility of lipid rafts, biochemically isolated from whole cells or lipid microvesicles without viral antigens, as alloimmunogens against SIV infection. However, as Dr. David Graham cautioned, for this strategy to succeed cells may need to be pretreated with Nef and Tat to mimic infection to account for possibly unique glycoforms of MHC proteins present during infection. The same treatment with accessory viral proteins might also be required if exosome microvesicles produced by MHC-expressing cell lines are considered as an alloimmunogen.

Noninfectious permeabilized aldrithiol-2 (AT-2)-treated virions or virion-associated lipid rafts (VALRs) are two forms of conformationally native alloimmunogen. Here, more than $90 \%$ of AT-2 virions are depleted of RNA and exhibit no TLR sensing, though $80 \%$ of MHC class I and II molecules are retained, rendering the empty virions powerful stimuli of $\mathrm{T}$ cell memory responses. ${ }^{26}$ VALRs contain enriched complexes of MHC class I/II and gp41/gp120, exhibit stability to freezing/thawing, display immunogenicity and feasible manufacturability in large quantities, and offer the possibility of employing MHC-Env complexes rather than MHC alone.

Discrete and well-defined MCM class I and II proteins might also be explored. Delivery of DNA plasmids via electroporation is likely to promote potent and specific B cell immune responses. Such an approach lends itself to manufacturability and straightforward demonstration of the role of each component from the standpoint of licensure. Along with the biochemical and biophysical standardization of the immunogens, an optimal adjuvant formulation would be essential for inducing the alloresponse. Though the panelists remained open to including viral antigens in the immunogen, the focus of the NHP pilot protocol remains to determine whether alloimmunization works by itself.

Skin graft transplantation was proposed by Dr. Allan Kirk as a viable experimental approach to determine if alloprotection exists, and if so, how broad it could be made. This strategy leads to well-characterized and potent alloantigenspecific immune responses and was rapidly accepted by the panel. The priority consensus of the panelists was to draft a protocol (Table 4) using male MCM with identical M1/M3 MHC haplotypes in vaccinee (matched M1/M3 MHC or disparate M4/M5 MHC of donor skin graft) and control (naive animals with no skin graft) groups to determine if MHC-disparate skin grafts result in effective alloimmunization against a repeated low-dose mucosal SIV $_{\text {mac239 }}$ challenge. Collected serum could be further used for passive transfer NHP studies to elucidate the role of antibody-mediated protection against the viral challenge.

\section{Immune responses}

The failures and limited successes of HIV/AIDS vaccines have highlighted the gaps in our knowledge with regard to fundamental immunity against HIV and have provided insight for vaccine strategies that might be implemented for designing more effective viral vaccines in the future. ${ }^{27}$ Recent studies have shown that robust mucosal immunity, high avidity and polyfunctional $\mathrm{T}$ cells, and broadly protective antibodies may be important factors governing the induction of protective immunity against HIV ${ }^{28}$ Also, it is anticipated that specific adjuvants and vectors can trigger innate immune signaling pathways that can improve the potency and quality of adaptive immunity. However, induction of long-term $\mathrm{T}$ and $\mathrm{B}$ cell memory, formulation of newer adjuvants with immunogens to retain conformational protective epitopes, and identification of immune correlates of protection against infection to reliably predict vaccine efficacy remain high priorities. Thus, it is essential that alternative strategies for HIV vaccines continue to be assessed. The Consultation addressed the immunologic characterization of the major components of the pilot NHP framework protocol. In addition to characterizing the functional profiles of $\mathrm{B}$ and $\mathrm{T}$ cells that may be required to prevent acquisition or restrict early infection, the Consultation suggested incorporating transcriptomic analyses that may identify specific alloresponse gene expression signatures.

\section{Assays and reagents resources}

MHC class I/II tetramers, coupled with flow cytometry, have emerged as important approaches for determining the specificity and phenotype of lymphocytes specific for any given antigen presented in the context of MHC. The characterization of MHC class II alleles is facilitating the generation of new MHC-peptide tetramers for exploring specific CD4 ${ }^{+}$ T-lymphocyte responses in NHP. Specifically, the low degree of polymorphism at the DRA locus in MCM allowed researchers to express MHC DRA-DRB heterodimers and explore the presentation of specific SIV peptides. ${ }^{29}$ Additionally, Kuroda and colleagues developed an MHC class II tetramer that could detect antigen-specific $\mathrm{CD} 4^{+}$cells in a rhesus macaque model of SHIV infection. ${ }^{30}$ It was suggested that MHC class I/II tetramers could possibly be used to label and track allo-B cells whose surface immunoglobulin is specific to allo-MHC. However, it remains to be determined if allo-B cell recognition is a significant proportion of B cell/ antibody response.

The enzyme-linked immunosorbent spot (ELISpot) is another highly sensitive, functional, and quantitative immunoassay to measure antigen-specific immune cells. T cell ELISpots can assess critical cellular immune-related activities such as interferon (IFN)- $\gamma$ secretion and granzyme B release. B cell ELISpots can detect and enumerate the number of antigenspecific B cells, the presence and frequencies of long-term memory B cells, and the total number of antibody-secreting cells. $^{31}$ By use of isotype-specific reagents, cells producing different isotypes (IgG, IgM, IgA, and IgE) can be analyzed separately. Thus, ELISpots provide not only a potency assay to assess the ability of a vaccine to induce an immune response, but also can be used as a biomarker of vaccine efficacy.

In addition, mass spectrometry and proteomic approaches could be used to characterize the alloimmunogen(s) and challenge virus, both antigenically and immunologically.

\section{Feasible next steps}

If initial MHC-disparate skin graft transplantation pilot experiments result in effective alloimmunization against 
mucosal SIV challenge, determining the immunologic correlates of protection against acquisition of infection and/or virologic control would be essential. Thus, alloprotected macaque sera could be further used for passive transfer NHP challenge studies to decode the protective role of anti-MHC antibodies. Knowing the vaccine-elicited immune responses that are associated with protection would potentially simplify developing immunogens that generate such immune responses. The group members unanimously acknowledged the need to establish a consensus, prior to performing a pilot NHP study, on what outcome(s) would actually constitute significant protection from acquisition, as it would guide and prioritize the next steps to answer the essential questions surrounding an alloimmunization-based vaccine strategy against AIDS.

Additionally, the Consultation members suggested complementing the protective effect of alloimmunization studies with epidemiologic research looking at HIV heterosexual transmission. The identification of additional human cohorts or databases associated with HLA typing was recommended to determine if the apparent protection from HIV acquisition observed is due to the presence of alloantibodies (e.g., in females with hemophiliac partners). Confounding risk factors, including female age and the number of pregnancies prior to their male partners becoming HIV infected, might further influence the effect of alloantibodies on HIV transmission and disease progression. The hypothesis that multiparous women, prior to their male partners becoming infected with HIV, are resistant to HIV infection needs to be more fully evaluated, and is expected to be valid across all ethnic groups.

\section{Conclusions}

The Consultation provided an opportunity for experts to revisit the alloantigen-based AIDS vaccine strategy for addressing, at least initially, whether alloimmunization by itself can induce a measurable degree of protection from virus acquisition, and to evaluate the current challenges and opportunities for rationally optimizing the design of a pilot NHP vaccination/challenge protocol. The panelists conducted an indepth discussion to reevaluate the unique advantages and disadvantages that an alloantigens-based prophylactic AIDS vaccine approach might impart. Multiple innate and adaptive immunologic factors, activated simultaneously by foreign HLA recognition, may create potentially synergistic responses that effectively protect against HIV /SIV infection. Importantly, alloimmunization approaches are of interest simply because they reasonably could overcome the major challenges of both unprecedented antigenic hypervariability of HIV/SIV and T-lymphocyte and/or antibody immune escape.

The panelists stressed that the questions and concerns regarding allo-mediated protection need to be answered in a highly controlled and well-defined experimental system. The members concurred that a skin graft transplantation pilot experiment would be the best initial option for directly determining if allo-protection exists, as this strategy leads to a well-characterized and potent alloimmune response. Priority consensus evolved to determine if MHC disparate (matched and mismatched) skin grafts in male MCMs with identical MHC haplotypes result in effective alloimmunization against a low-dose repeated intrarectal $\mathrm{SIV}_{\text {mac239 }}$ challenge. Such a model would provide better insight into the potential utility of alloimmunity-based vaccines following a physiologically relevant virus exposure. If alloimmunization in a pilot NHP protocol results in effective or even partially effective protection, this would provide a basis to further explore the immune and genetic correlates of such protection. Furthermore, the negative result may not preclude the possibility that MHC antigens presented in the context of virus infection, alone or in combination with viral antigens, may play a role in protection. The resulting conceptual advancements might lead to further new and advanced immunologic read-outs (i.e., novel biomarkers) for vaccineinduced immune responses.

The Consultation members considered major clinical issues, safety concerns, regulatory obligations, reproductive toxicology questions, and ethical considerations to determine if the proposed allogeneic immunization studies in NHP would be translatable to human studies. Though not specifically discussed in detail at the consultation, there are two major issues not often discussed regarding alloimmunization approaches: (1) what would the actual constituents be of an allovaccine, and (2) would prior HLA typing be required as part of a formal vaccination program? As to the first question, preclinical and early phase 1 clinical studies would need to suggest the minimum number of different HLA proteins required, and whether ethnic-specific or region-specific vaccines are required. The number, frequency, and distribution of HLA alleles would need to be well known regionally if not globally. The second question on the risk of breaking tolerance and creating autoimmunity could also be addressed experimentally in preclinical studies in NHP and in early phase 1 clinical studies. As an effective alloresponse-based vaccine would need to cover the majority of HLA types, it might suggest that anyone who has ever been vaccinated in this manner would face substantial obstacles to or be ineligible for a subsequent organ transplant or blood component transfusion. This is especially relevant as HIV-infected individuals have an increased risk of kidney and liver failure than the general population. In general, $30-35 \%$ of all people are estimated to be sensitized with HLA antigens; the presence of antibodies to a broad array of HLA antigens is a major bar to transplantation. Desensitization protocols to reduce preexisting HLA antibodies to a level that allows for successful engraftment are not always successful.

As a broad consensus it was recognized that the alloimmunization approach is not at the stage of developing a translatable vaccine, but at the stage of being a basic science question, which should be asked without being constrained at this stage of research by whether this can be done in people. The gains in knowledge of alloimmunity and/or tolerance induction and duration of immune responses gleaned from preclinical research might inform the fields of transplant biology and hematology.

\section{Acknowledgments}

The authors would like to thank the panelists and participants for their presentations, recommendations, and participation in the discussions. We also acknowledge the NIAID-wide Organizing Committee: Nancy Bridges, Anthony Conley, Kristy Kraemer, Stuart Shapiro, Charles Hackett, Alan Schultz, Opendra Sharma, Anjali Singh, and Jon Warren for their help in planning and moderating the 
Consultation. We are grateful to Carl Dieffenbach, Diana Finzi, Susan Plaeger, and Kevin Ryan for their support.

The views expressed in this article are those of the authors and do not necessarily reflect the official policies of the Department of Health and Human Services. This workshop was supported by funds from the NIAID Division of AIDS.

\section{Author Disclosure Statement}

No competing financial interests exist.

\section{References}

1. Shearer GM, Clerici M, and Dalgleish A: Alloimmunization as an AIDS vaccine? Science 1993;262:161-162.

2. Lehner T, Shearer GM, Hackett CJ, Schultz A, and Sharma OK: Alloimmunization as a strategy for vaccine design against HIV/AIDS. AIDS Res Hum Retroviruses 2000;16: 309-313.

3. Carrington M and O'Brien SJ: The influence of HLA genotype on AIDS. Annu Rev Med 2003;54:535-551.

4. Pereyra F, Jia X, McLaren PJ, Telenti A, de Bakker PIW, Walker BD, et al.: Study TIHC: The major genetic determinants of HIV-1 control affect HLA class I peptide presentation. Science 2010;330:1551-1557.

5. Kind C, Nadal D, Wyler C-A, Siegrist C-A, Cheseaux JJ, Vaudaux B, Fawer C-L, Rudin C, and Schaad UB: Mother-tochild transmission of human immunodeficiency virus type 1 : influence of parity and mode of delivery. Eur J Pediatr 1995; 154:542-545.

6. Clerici M, DePalma L, Roilides E, Baker R, and Shearer GM: Analysis of $\mathrm{T}$ helper and antigen-presenting cell functions in cord blood and peripheral blood leukocytes from healthy children of different ages. J Clin Invest 1993;91:2829-2836.

7. MacDonald KS, Embree J, Njenga S, Nagelkerke NJ, Ngatia I, Mohammed Z, Barber BH, Ndinya-Achola J, Bwayo J, and Plummer FA: Mother-child class I HLA concordance increases perinatal human immunodeficiency virus type 1 transmission. J Infect Dis 1998;177:551-556.

8. Biasin M, Piacentini L, Lo Caputo S, Kanari Y, Magri G, Trabattoni D, Naddeo V, Lopalco L, Clivio A, Cesana E, Fasano F, Bergamaschi C, Mazzotta F, Miyazawa M, and Clerici M: Apolipoprotein B mRNA editing enzyme, catalytic polypeptide-like 3G: A possible role in the resistance to HIV of HIV-exposed seronegative individuals. J Infect Dis 2007;195:960-964.

9. Kingsley C, Peters B, Babaahmady K, Pomeroy L, Rahman D, Vaughan R, and Lehner T: Heterosexual and homosexual partners practising unprotected sex may develop allogeneic immunity and to a lesser extent tolerance. PLoS ONE 2009; 4:e7938.

10. Arthur LO, Bess JW Jr, Sowder RC II, Benveniste RE, Mann DL, Chermann JC, and Henderson LE: Cellular proteins bound to immunodeficiency viruses: Implications for pathogenesis and vaccines. Science 1992;258:1935-1938.

11. Golding H, Shearer GM, Hillman K, Lucas P. Manischewitz J, Zajac RA, Clerici M, Gress RE, Boswell RN, and Golding B: Common epitope in HIV I-GP41 and HLA class II elicits immunosuppressive autoantibodies capable of contributing to immune dysfunction in HIV-infected individuals. J Clin Invest 1989;83:1432-1435.

12. Arthur LO, Bess JW Jr, Urban RG, Strominger JL, Morton WR, Mann DL, Henderson LE, and Benveniste RE: Macaques immunized with HLA-DR are protected from challenge with simian immunodeficiency virus. J Virol 1995;69:31173124.

13. Stott EJ: Protection against simian immunodeficiency virus infection of macaques by cellular or viral antigens. Neuvième Colloque des Cent Gardes 1994;219-224.

14. Stott EJ, Kitchin PA, Page M, Flanagan B, Taffs LF, Chan WL, Mills KHG, Silvera P, and Rodgers A: Anti-cell antibody in macaques. Nature 1991;353:393.

15. Stott J, Wade-Evans A, Walker B, Stebbings R, Ranjbar S, Hull R, Kent K, Bootman J, Jones S, Rose J, Silvera P, Sangster R, Corcoran T, Silvera K, and Almond N: Vaccineinduced protection in macaques: Implications for HIV and the enigma of attenuated SIV. Onzième Colloque des Cent Gardes 1997;235-244.

16. Polyanskaya N, Sharpe S, Cook N, Leech S, Banks J, Dennis M, Hall G, Stott J, and Cranage M: Anti-major histocompatibility complex antibody responses to simian B cells do not protect macaques against SIVmac infection. AIDS Res Hum Retroviruses 1997;13:923-931.

17. Yang G-B, Wang Y, Babaahmady K, Scholler J, Rahman D, Bunnik E, Spallek R, Zong C-M, Duan J-Z, Qin C, Jiang H, Singh M, Vaughan R, Bergmeier LA, Schuitemaker H, Shao $\mathrm{Y}$, and Lehner T: Immunization with recombinant macaque major histocompatibility complex class I and II and human immunodeficiency virus gp140 inhibits simian-human immunodeficiency virus infection in macaques. J Gen Virol 2012;93:1506-1518.

18. Bergmeier LA, Babaahmady $\mathrm{K}$, Wang $\mathrm{Y}$, and Lehner $\mathrm{T}$ : Mucosal alloimmunization elicits T-cell proliferation, CC chemokines, CCR5 antibodies and inhibition of simian immunodeficiency virus infectivity. J Gen Virol 2005;86:22312238.

19. Wang Y, Underwood J, Vaughan R, Harmer A, Doyle C, and Lehner T: Allo-immunization elicits CCR5 antibodies, SDF-1 chemokines, and CD8-suppressor factors that inhibit transmission of R5 and X4 HIV-1 in women. Clin Exp Immunol 2002;129:493-501.

20. Leith JG, Clark DA, Matthews TJ, Rosenthal KL, Luscher MA, Barber BH, and MacDonald KS: Assessing human alloimmunization as a strategy for inducing HIV type 1 neutralizing anti-HLA responses. AIDS Res Hum Retroviruses 2003;19:957-965.

21. Coulam CB, Collins J, Scott JR, and Schlesselman JS: Worldwide collaborative observational study and metaanalysis on allogenic leukocyte immunotherapy for recurrent spontaneous abortion. Am J Reprod Immunol 1994;32: $55-72$.

22. Shearer GM and Boasso A: Alloantigen-based AIDS vaccine: Revisiting a "rightfully" discarded promising strategy. F1000 Med Rep 2011;3:12.

23. Budde ML, Wiseman RW, Karl JA, Hanczaruk B, Simen BB, and $\mathrm{O}^{\prime}$ Connor DH: Characterization of Mauritian cynomolgus macaque major histocompatibility complex class I haplotypes by high resolution pyrosequencing. Immunogenetics 2010; 62:773-780.

24. Mee ET, Berry N, Ham C, Aubertin A, Lines J, Hall J, Stebbings R, Page M, Almond N, and Rose NJ: MHC haplotype M3 is associated with early control of SHIVsbg infection in Mauritian cynomolgus macaques. Tissue Antigens 2010;76:223-239.

25. Feinberg MB and Moore JP: AIDS vaccine models: Challenging challenge viruses. Nat Med 2002;8:207-210.

26. Boasso A, Royle CM, Doumazos S, Aquino VN, Biasin M, Piacentini L, Tavano B, Fuchs D, Mazzotta F, Lo Caputo S, 
Shearer GM, Clerici M, and Graham DR: Overactivation of plasmacytoid dendritic cells inhibits antiviral T-cell responses: A model for HIV immunopathogenesis. Blood 2011;118: 5152-5162.

27. Rerks-Ngarm S, Pitisuttithum P, Nitayaphan S, Kaewkungwal J, Chiu J, Paris R, Premsri N, Namwat C, de Souza M, and Adams E: Vaccination with ALVAC and AIDSVAX to prevent HIV-1 infection in Thailand. N Engl J Med 2009; 361:2209-2220.

28. McElrath J and Haynes BF: Induction of immunity to human immunodeficiency virus type- 1 by vaccination. Immunity 2010;33:542-554

29. Dzuris JL, Sidney J, Horton H, Correa R, Carter D, Chesnut RW, Watkins DI, and Sette A: Molecular determinants of peptide binding to two common rhesus macaque major histocompatibility complex class II molecules. J Virol 2001;75: 10958-10968.

30. Kuroda MJ, Schmitz JE, Lekutis C, Nickerson CE, Lifton MA, Franchini G, Harouse JM, Cheng-Mayer C, and Letvin NL: Human immunodeficiency virus type 1 envelope epitope-specific CD4(+) T lymphocytes in simian/human immunodeficiency virus-infected and vaccinated rhesus monkeys detected using a peptide-major histocompatibility complex class II tetramer. J Virol 2000;74:8751-8756.

31. Slota M, Lim JB, Dang Y, and Disis ML: ELISpot for measuring human immune responses to vaccines. Expert Rev Vaccines 201;10:299-306.

Address correspondence to: Opendra Sharma National Institutes of Health 6700-B Rockledge Drive, Room 4151 Bethesda, Maryland 20892-7626

E-mail: os4g@nih.gov

Anjali Singh

National Institutes of Health

6700-B Rockledge Drive, Room 5260

Bethesda, Maryland 20892-7628

E-mail: anjalisingh@niaid.nih.gov 